\title{
The Influence of Children's structure on Rural Intergeneration Resources Exchange Mechanism *
}

\author{
Tao Yuchun, Shen Yu \\ School of Economics and Management, East China Jiaotong University, Jiangxi Province, China
}

\begin{abstract}
Using the data from "china health and retirement longitudinal study" in 2013, employing the generalized linear model and logistic regression analysis, It is founds that there is division of labor and replacement between children either in financial support or emotional support to meet the various requirements of elderly. The birth order and gender of children have a significant impact on the intergenerational resources transfer, the quantity and gender of grandchildren have a significant impact on the motivation, and the factors of distance, migration and caring for grandchildren cannot be ignored.
\end{abstract}

Index Terms - the structure of children, rural elderly, grandchildren caregiving, intergenerational resources exchange

\section{Introduction}

As the growth of the average life expectancy and the fallen of fertility, the structure of population age trend to be aging. When the per capita income level is in low and middle level, the economy is undeveloped, old-age security system is imperfection, China has step into the age of aging. Then Most of the elderly population living in rural areas, which areas of economic development level is relatively backward, combined with insufficient national support and resources to provide social security. The vast majority of rural elderly are supported by their adult children, so the research on intergenerational support is particularly important.

Under the background of modern family structure, domestic researches on the subject that the influence of family structure characteristics on the rural elderly endowment are less. The advancement of urbanization promote the outflow of rural labor, social mobility enhancement has impact on the traditional family structure, whether family function is changed or not, and what effect have made by family intergenerational support is related to the problem of rural elderly pension.

\section{The Theory and Hypothesis}

Intergenerational support is mainly about the transfer of money and service. Monetary intergenerational support include cash, physical objects and the transfer of real estate, service transfer include the transfer of daily care and emotional support, etc. Resource exchange direction into top-down and bottom-up, namely the older generation to the younger generation of resources and the younger generation to the resources of the older generation.

\section{A. The Theory of Intergenerational Support Motivation}

Regarding to the motivation of intergenerational support, altruism theory emphasizes that the purpose of help behavior is simplicity and not for the reward or return. Exchange theory emphasizes that behavior brings reward and remuneration of exchange activities. Cox, Hansen (2004) argue that before the transfer to set up a perfect public economy, the motivation of altruism is a shift in the private economy. After the parents take care of their grandchildren, exchange of motivation will be more economic than transfer motivation. Concerning the research on the impact of a large number of rural labor flow to the nonlocal places on intergenerational relations of rural households, Sun Juanjuan (2006) argue that outgoing children tend to give more economic support to make up the absence of daily care. Hisam Kim (2010) argue that parents spend a lot of time to take care of the next generation of their children, then the adult children ,based on the Exchange theory, provide more financial support as the remuneration [1].Thus:

Hypothesis 1. The behavior of supporting the rural elderly from adult children who have child is based on the exchange motivation.

Hypothesis 2. The behavior of supporting the rural elderly from children who are working outside is based on the altruism motivation.

\section{B. The Theory of Intergenerational Support Ability}

A push-pull theory points out that after adult children are working out, a lot of factors, such as human geography, obstacle factors, individual factors, come in being two utility, that is thrust and tension. Wilensky (2002) argue that when the younger generation work out, their values will change, which will weaken the traditional concept of filial piety and the willingness and ability to support their parents. Yan ShanPing (2007) pointed out that the greater the geographic space distance between the generations, the greater power of the thrust, a wide range of movement between provinces costs increased, and adapting to a new living environment also need to pay more cost of material and spiritual [2]. Li Shuzhuo (2010) argue that children who lives farther from the elderly provide more economic returns, but less caregiving [3].The distance between every child's and parents' lives is different, so the form of intergenerational support also changes, which is based on the advantages and situation of each child. Thus:

Hypothesis 3. Migration for working help the children to improve the ability of intergenerational support.

Hypothesis 4 . The difference of the living distance have a significant influence on intergenerational support.

\footnotetext{
${ }^{*}$ This work is partially supported by the Humanities and Social Science project from Ministry of Education Grant \#12YJA30109
} 
With the improvement of women's economic ability and the family status, the difference of intergenerational support by gender are changed in rural family. Whyte (2003) point out that sons are more likely to provide economic support to his parents than daughters, from the view of elderly. Yu Xie (2009) argue that the married daughters give more economic support to his parents than sons, from the perspective of children [4]. Zhang Hangkong (2012) argue that if parents have no sons, their daughter will take place the role of son, differences of intergenerational support by gender will reduced, according to the order of caregiving support, emotional support and financial support[5]. Zhou Lv (2012) found that the order of children's birth have significant effects on intergenerational transfer, and the impact of children's gender is not significant [6]. Thus:

Hypothesis 5.The gender of children have significant effects on intergenerational resource exchange mechanism.

Hypothesis 6. The order of children's birth have significant effects on intergenerational resource exchange mechanism.

\section{The Instructions of Data and Variable}

In this paper, the data is from "china health and retirement longitudinal study" in 2013, using the multistage stratified sampling method, and choosing the rural elderly samples which is aged 60 and above. Then the data is consist with 942 family samples, 1526 parents samples and 2999 matched adult children samples.

\section{A. The Instructions of Dependent Variable}

Intergenerational monetary transfer is based on the economic help from children during the past year. Economic support includes financial help, such as giving money, helping pay bills, covering specific costs, and providing non-monetary goods. Intergenerational service transfer includes taking care of parents during the last month in assisting them in daily activities or other activities, such as household chores, meal preparation, laundry, going out, grocery shopping, financial management, and whether children often visit or not, whether children lived alone have contact by phone, text, mail, email or not. Every question has two options, one is "yes" and the other is "no", if the respondents choose "yes", he will get one point. Then, the numerical value of emotional support variables is the total score of questions.

\section{B. The Instructions of Independent Variables}

The characteristic variables of elderly parents include age, marital status, level of education, number of children, the physiological health, psychological health, chronic diseases and grandchildren caregiving. Elderly parents' physical health is diagnosed by the ability of daily life self-care and chronic disease, which refer to the Activities of Daily Life Scale (ADL) and Instrumental Activities of Daily Living Scale (IADL).

Children's characteristic variables include gender, age, marital status, occupation, education status, living distance, the quantity of sons, the quantity of daughters, and the situation of migrant workers. In order to effectively distinguish the children of older generation and the children of younger generation, in this paper, grandchildren means the children of younger generation, which is from the view of older generation.

\section{The Empirical Analysis}

\section{A. The Influence of Children's Birth Order on Rural} Intergeneration Support

Using the backward conditions regression to reject the indistinctive independent variables in Logistic model, at first, choosing the variable that whether the children provide economic support to his/her parents or not as the dependent variable. In the same family sample, making a comparison with the first child, the second child, the third child and the fourth one to analysis their helping behavior. There are more than four children in some family, namely the fourth child above-mentioned doesn't means the youngest child.

TABLE I Logistic Regression Analysis of Intergenerational Monetary Transfer from Different Birth-ordered Child

\begin{tabular}{|c|c|c|c|c|}
\hline Odds Ratio & $\begin{array}{c}\text { The Fourth } \\
\text { Child }\end{array}$ & $\begin{array}{l}\text { The Third } \\
\text { Child }\end{array}$ & $\begin{array}{c}\text { The Second } \\
\text { Child }\end{array}$ & $\begin{array}{l}\text { The First } \\
\text { Child }\end{array}$ \\
\hline Child's Gender & $8.238 * *$ & & $0.123 * *$ & \\
\hline Working out & $0.124^{*}$ & & & \\
\hline Age & & $1.154 * *$ & $1.083 * *$ & $1.137 * *$ \\
\hline Living Distance & & $0.581^{*}$ & 1.189 & \\
\hline Number of Sons & 3.769 & $12.071 * *$ & & $2.553^{*}$ \\
\hline Number of Daughters & $11.162 * *$ & 2.094 & $2.779 * *$ & $3.903 * *$ \\
\hline Education Level & & $16.734 * *$ & & $2.552 * *$ \\
\hline Parents' Age & & & & $0.883^{* *}$ \\
\hline Number of Children & & & $0.536 * *$ & \\
\hline Education Level & 1.98 & & $1.881^{*}$ & $2.144 * *$ \\
\hline $\mathrm{ADL}$ & $1.35^{* *}$ & $1.402 * *$ & & $1.689 * *$ \\
\hline IADL & $2.206 * *$ & $2.294 * *$ & & \\
\hline $\begin{array}{l}\text { Taking Care of } \\
\text { Grandchildren }\end{array}$ & $7.039 *$ & & & \\
\hline
\end{tabular}

$* \mathrm{p}<0.05, * * \mathrm{p}<0.01$

Researches show that if younger generation have many children, they are inclined to give more economic support to their parents. The higher education background child have, the more finical support will give to parents. If parents complete higher level of education, the more financial support they will receipt. The poor physical health of parents, the more financial support the children will give.

For the first child, the eldest son give more economic support to parents than others, the number of sons is closely relative to the quantity of financial support for parents. If parents' daily self-care ability is poor, the eldest son will give 
more financial support. For the second child, daughters will give more economic support than sons. If child is living far away from parents, the probability of giving more economic support from them will higher. More brothers and sisters the second son have, lower probability to give financial support. For the third child, children's age, number of sons, daughters, record of formal schooling and is closely relative to intergeneration financial support. For the fourth child, sons have higher probability to give parents financial support. The poor physical health of the parents, the more the economic support they will have. Children will give more financial support because their parents take care of grandchildren. Compare the second child with the fourth child, child with different gender will make opposite effect on intergenerational economic exchanges. Compare the second child with the third one, child with different living distance from parents will have the opposite effect on intergenerational economic exchanges.

\section{B. The variance analysis between eldest child and youngest child on rural intergeneration exchange}

The eldest child and youngest child act different role in rural family, the eldest child have more responsibility for the family, while parents preferred to the youngest child. So discussion about the special situation in rural family is necessary. In the form of Logistic response, we structure a generalized linear model, then change the dependent variable and independent variables of children's characteristic into 0,1 variables for analysis.

As the elderly person has a spouse to help each other, the eldest child will give more financial support instead of emotional support. When the child working outside, there is less time to take care of his parents, so other children who are working at home will give more emotional support to make up the absence of the eldest one, then the out-work child will send more cash to parents. The youngest son give more financial support to parents, while the youngest daughter give more emotional support. As the eldest child, when the youngest child work out, he/she will give more financial help to make up the absence of emotional care. The division of labor is clear-up, each child being charged with specific responsibility.

When elderly have been diagnosed with chronic disease by doctors, more financial compensation given to parents for hospitalization costs, but less from the emotional support. After parents have lost the ability of instrumental activities of daily living, their child will take more attention to them, and give more emotional care. When child get married and live away from parents, he/she will shift his/her attention to the new family, meanwhile he/she will neglect their parents, especially affection interaction.

As parents spend a lot time on taking care of grandchildren, the eldest child will increase the financial costs as the payment. Child will show more loving care for their children, the emotional care that parents obtain haven't changed obviously despite taking care of the child's children.
TABLE II Variance Analysis between Eldest Child and Youngest Child on Rural Intergeneration Exchange

\begin{tabular}{|c|c|c|c|c|}
\hline \multirow{2}{*}{ Variable } & \multicolumn{2}{|c|}{ The Eldest Child } & \multicolumn{2}{|c|}{ The Youngest Child } \\
\hline & $\begin{array}{c}\text { Financial } \\
\text { Support }\end{array}$ & $\begin{array}{c}\text { Emotional } \\
\text { Support }\end{array}$ & $\begin{array}{c}\text { Financial } \\
\text { Support }\end{array}$ & $\begin{array}{l}\text { Emotiona } \\
1 \text { Support } \\
\end{array}$ \\
\hline Child's Gender: female & 0.268 & $-0.587^{*}$ & -0.106 & $0.641^{*}$ \\
\hline Not working out & $2.483^{* *}$ & $-1.448^{* *}$ & 1.388 & 0.455 \\
\hline Being married & 20.659 & -0.41 & 19.796 & -0.452 \\
\hline Parents' Age & $0.046^{* *}$ & $-0.061 * *$ & -0.015 & $-0.014 *$ \\
\hline Education & 0.003 & -0.069 & $-0.268 *$ & -0.074 \\
\hline Marriage & $0.622 *$ & $-0.809 *$ & -0.333 & $-0.397 *$ \\
\hline Chronic disease & 0.037 & -0.316 & $-0.323^{*}$ & 0.022 \\
\hline $\mathrm{ADL}$ & $-0.058^{*}$ & $-0.227 *$ & $0.189^{* *}$ & 0.015 \\
\hline IADL & -0.028 & $0.279 * *$ & 0.018 & $0.143 * *$ \\
\hline Mental Health & $-0.045 * *$ & -0.023 & $0.058 * *$ & $-0.046^{*}$ \\
\hline Living Distance & $-0.098^{*}$ & $-0.217^{*}$ & $0.478 * *$ & $-0.338^{*}$ \\
\hline $\begin{array}{l}\text { Taking Care of } \\
\text { Grandchildren }\end{array}$ & $0.838^{*}$ & $-1.5^{* *}$ & $1.207^{*}$ & -0.84 \\
\hline \multicolumn{5}{|l|}{ Cross Term } \\
\hline $\begin{array}{l}\text { Grandchildren } \\
\text { Caregiving * Grandson }\end{array}$ & $1.26^{*}$ & $-1.379 * *$ & & \\
\hline $\begin{array}{l}\text { Grandchildren } \\
\text { Caregiving * } \\
\text { Granddaughter } \\
\end{array}$ & & & $0.486^{*}$ & 2.298 \\
\hline $\begin{array}{l}\text { Granddaughter } \\
\text { Caregiving *Working } \\
\text { at Home }\end{array}$ & $-2.802 * *$ & $1.491 * *$ & $-1.47 *$ & -0.194 \\
\hline Intercept & $-1.496^{* *}$ & $5.933 * *$ & $-5.564 * *$ & $-0.757 * *$ \\
\hline
\end{tabular}

\section{The Influence of Children's gender on rural intergeneration support}

Compared to child whose house located in another country in the same province, child who lives in the same county give less financial support to parents, sons lived in the same county give more emotional support than daughters. There is a complementary relationship between the son and daughter in the aspect of working out, male migrant worker make more money than female, so out-working son improve the capacity to support parents, under the action of altruism, he will give parents more economic support, then emotional support is mainly given by daughter.

Children have more brothers or sisters, they inclined to give parents more financial support and emotional support. Parents' education level is higher, in general, it means that the parents' income level is higher, as well as the relatively higher social status, at the same time, their children's emotional support become the important resources for parents. When parents' daily life ability get weak, children will give more financial support. When Parents' mental health deteriorated, son will give more emotional support, and daughter give more 
financial support. After parents have chronic disease, the financial support from children changes little, however the emotional support strengthened.

TABLE III Analysis of Intergenerational Monetary Transfer from Child of Different Gender

\begin{tabular}{|l|c|c|c|c|}
\hline \multirow{2}{*}{ Coefficient } & \multicolumn{2}{|c|}{ Son } & \multicolumn{2}{c|}{ Daughter } \\
\cline { 2 - 5 } & $\begin{array}{l}\text { Financial } \\
\text { Support }\end{array}$ & $\begin{array}{l}\text { Emotional } \\
\text { Support }\end{array}$ & $\begin{array}{l}\text { Financial } \\
\text { Support }\end{array}$ & $\begin{array}{l}\text { Emotional } \\
\text { Support }\end{array}$ \\
\hline $\begin{array}{l}\text { Child's Living } \\
\text { Arrangement: } \\
\text { Another Country in the } \\
\text { Same Province }\end{array}$ & $-0.963^{* *}$ & $0.673^{*}$ & $-0.263^{*}$ & -0.259 \\
\hline Out-working: no & -0.027 & $0.292^{*}$ & 0.261 & -0.852 \\
\hline $\begin{array}{l}\text { Parents' Take Care of } \\
\text { Grandchildren: no }\end{array}$ & -0.555 & -0.229 & $0.595^{*}$ & $0.757^{*}$ \\
\hline Number of Children & $0.135^{*}$ & -0.046 & $0.136^{*}$ & 0.131 \\
\hline Education Level & $-0.578^{*}$ & $0.835^{* *}$ & $-0.471^{*}$ & $0.305^{*}$ \\
\hline ADL & $0.508^{* *}$ & $-0.239^{*}$ & $0.428^{* *}$ & -0.051 \\
\hline IADL & 0.064 & 0.035 & -0.006 & 0.06 \\
\hline Mental Health & 0.006 & 0.013 & $0.026^{* *}$ & -0.016 \\
\hline Chronic disease & -0.462 & $0.77^{*}$ & $-0.786^{* *}$ & $0.757^{* *}$ \\
\hline Marriage & 0.155 & $0.853^{* *}$ & $0.318^{*}$ & $0.325^{*}$ \\
\hline Cross Term & $-4.672^{* *}$ & $1.8^{*}$ & $-5.707^{* *}$ & $2.857^{*}$ \\
\hline $\begin{array}{l}\text { Grandchildren } \\
\text { Caregiving * Number of } \\
\text { Grandchildren }\end{array}$ & $1.38^{* *}$ & $2.508^{* *}$ & 0.081 & $0.98^{* *}$ \\
\hline $\begin{array}{l}\text { Living in Another } \\
\text { Country * not taking } \\
\text { care of grandchildren }\end{array}$ & 0.52 & $-0.559^{*}$ & 2.609 & -0.157 \\
\hline Intercept & \multicolumn{5}{|r|}{} \\
\hline
\end{tabular}

\section{Conclusions}

The birth order of children have a significant impact on the resource exchange mechanism, so the hypothesis 6 has been demonstrated. The eldest children will not reduce the emotional support and emotional support despite their parents didn't take care of granddaughter, namely the motivation of assistance are altruistic. If elderly parents take care of grandson, the eldest children will give more financial support. The youngest child will increase the financial and emotional support to parents for granddaughter caregiving, which is based on exchange motivation.

When child living in another county in the same province, parents will receipt more financial support for taking care of grandchildren, so hypothesis 4 has been proved. According to Act-utilitarianism of resources allocation, children achieve the goal of caring for elderly parents at the minimum cost, the youngest children lived far away from parents will give more financial support to make up for the lack of emotional support. When parents take care of granddaughter, the youngest children don't increase financial and emotional support, it proved again that the gender of grandchildren affect children's intergenerational support motivation.

Working out bring about the improvement in economic conditions, children are more able to provide financial help, the child who are working out take the role of financial support provider in intergenerational exchange and traditional division of family pension mode, while the other children are responsible for caregiving and services. The eldest children give parents more money for grandchildren caregiving as economic compensation, but give less emotional support, this behavior is based on the theory of exchange motivation. Workout children who are the youngest will provide more financial support and emotional support, their motivation is altruistic. Migration for working help the children to improve the ability of intergenerational support, so hypothesis 3 is proved.

The children with different gender adopt different strategies for elderly caregiving. According to the arrangement of living in country, daughter generally lives in another country which is away from parents after she got married, and son is usually lives with their parents in the same village. In terms of geographical spatial accessibility, son cost less to meet the parents, there is higher probability to give intergenerational support. Although daughter living relatively far away meet their parents less frequently, it is more likely to maintain contact as compensation. The gender of children have significant effects on intergenerational resource exchange mechanism, so the hypothesis 5 has been demonstrated.

Since the service of left-behind children daily-care is not widely received in country, elderly parents become the important resource of taking care of grandchildren after children working out. As number of child's children become more and more, the limitation of children's ability and financial resources makes the elderly parents compete with grandchildren in terms of economic and emotional support. At that time, children tend to spend more money or time meeting their children's demand, meanwhile reducing the elderly of intergenerational support. So the factor of caring for grandchildren cannot be ignored.

\section{References}

[1] Hisam Kim. "Intergenerational Transfers and Old-Age Security in Korea," The Economic Consequences of Demographic Change in East Asia, vol. 19, no.8, pp.227-278, 2010.

[2] Yan Shanping. "Inter-provincial Migration and Its Determinants in the 1990's China," Chinese Journal of Population Science, vol. 9, no. 1, pp.71-77, 2007.

[3] Song Lu, Li Shuzhuo. "The Impact of Care for Grandchildren on Intergenerational Support of the Elderly in Rural China," Population Journal, vol.12, no. 1, pp.35-38, 2010.

[4] Yu Xie. "Do Sons or Daughters Give More Money to Parents In Urban China?" Journal of Marriage and Family, pp.174-186, 2009.

[5] Zhang Hongkong. "Sons, Daughters and Intergenerational Support," Population and Development, pp.17-21, 2012.

[6] Zhou Lv. "Impact of Children's Gender and Birth Order on Intergenerational Economic Transfer in Rural China," Population Journal, pp.52-60, 2012. 